\title{
Analysis of the Rheological Behavior of Aging Bitumen and Predicting the Risk of Permanent Deformation of Asphalt
}

\author{
Samia Saoula $^{{ }^{*}}$, Khedoudja Soudani ${ }^{1}$, Smail Haddadi $^{1},{\text { Maria Eugenia } \text { Munoz }^{2} \text {, Antxon Santamaria }}^{2}$ \\ ${ }^{1}$ Laboratory of Environment, Water Geomechanics and Structures, Faculty of Civil Engineering, University of Sciences and Tech- \\ nology Houari Boumediene, Algiers, Algeria; ${ }^{2}$ Department of Science and Technology of Polymers, Faculty of Chemistry, Univer- \\ sity of the Basque Country, San Sebastian, Spain.

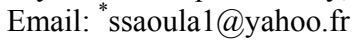

Received February $27^{\text {th }}, 2013$; revised April $2^{\text {nd }}, 2013$; accepted April $14^{\text {th }}, 2013$

Copyright (C) 2013 Samia Saoula et al. This is an open access article distributed under the Creative Commons Attribution License, which permits unrestricted use, distribution, and reproduction in any medium, provided the original work is properly cited.

\begin{abstract}
The aging of bitumen has a significant impact on the mechanical behavior of asphalt. This aging is carried out at the mixing operation with the aggregates generally at $163^{\circ} \mathrm{C}$ in the case of pure mixtures or at temperatures higher than in the case of the modification by polymers or industrial waste. This paper presents experimental results of a study of the rheological behavior of a class of bitumen $40 / 50$ to the artificial aging. Three aging temperatures were selected: $163^{\circ} \mathrm{C}$, $173^{\circ} \mathrm{C}$ and $183^{\circ} \mathrm{C}$. From obtained results, a study of the risk of deformation of asphalt is performed, based on the results of correlation between the behavior of the coated and his binder deducted SHRP specifications and technical advice French. These results show that the stiffness of the aged binders increases with aging temperature. Moreover, there is no risk of rutting and fatigue cracking for thermal coated projected.
\end{abstract}

Keywords: Aging; Bitumen; Rheology; Deformation; Rutting

\section{Introduction}

Bituminous binders are widely used for road paving applications [1]. The ageing of the bitumen during storage, mixing, transport and laying on the road, as well as in service life, are the most important problems presented by the use of bitumen in pavements [2].

Indeed, Bitumen ageing is a very complex process resulting in hardening of bitumens and embrittlement, both in application and in service, which contributes greatly to the deterioration of paving applications [3].

Important ageing related modes of failure are traffic and thermally induced cracking, and ravelling and shorten the lifespan of pavement $[4,5]$.

In bitumen aging, two types of mechanisms are involved. The main aging mechanism is an irreversible one, characterised by chemical changes of the binder, which in turn has an impact on the rheological properties [6]. The second mechanism is a reversible process called physical hardening $[7,8]$. Physical hardening may be attributed to molecular structuring [5].

Several methods have been proposed to replicate the effect of aging and, therefore, to foresee bitumen behav-

${ }^{*}$ Corresponding author. ior during application and service life. To simulate the age hardening occurring during plant mixing and laydown the most utilised test is Rolling Thin Film Oven Test (RTFOT, ASTM D-2872). The age hardening is evaluated by observing how viscosity, penetration and softening point change with aging [3]. Aging, which occurs in asphalt roadway pavements during construction and service life, affect the rheological properties of bitumen $[5,8]$.

Rheology involves the study and evaluation of the time - temperature dependent response of materials that are stressed or subjected to an applied force. Rheological properties of bitumen consist of age hardening, temperature susceptibility, shear susceptibility, stiffness, penetration, ductility, and viscosity [9].

Over the past few years, rheology has been extensively used in order to classify and evaluate bituminous binders according to their performance properties. This has led to a better knowledge of bitumen behaviour that occurs when subjected to different thermal and mechanical conditions, as seen during road construction and service in the field [3].

One of the key material properties of bitumen is the complex modulus. This property is related to major dis- 
tress modes such as traffic induced permanent deformation and rutting, as well as fatigue and low temperature cracking. The complex modulus is dependent upon temperature and loading frequency [10].

This paper presents experimental results of a study of the rheological behavior of a class of bitumen 40/50 to the artificial aging. Three aging temperatures were selected: $163^{\circ} \mathrm{C}, 173^{\circ} \mathrm{C}$ and $183^{\circ} \mathrm{C}$.

In this work, test aging was evaluated by means of complex modulus $\left(\mathrm{G}^{*}\right)$ and phase angle $(\delta)$, determined by dynamic rheological analysis.

From the results obtained a study of the risk of deformation of asphalt has been achieved, based on the results of correlation between the behavior of the coated and his binder deducted SHRP specifications and technical advice French.

\section{Materials}

The bitumen of class of 40/50 (B) used in this study is commercialized by NAFTAL. The main physical properties of the bituminous material are the following: penetration (at $25^{\circ} \mathrm{C} 1 / 10 \mathrm{~mm}$ ) $=27$, softening point temperature $=54.9^{\circ} \mathrm{C}$ and penetration index $(\mathrm{PI})=-1.33$.

Ring and ball temperature is considered as a value attached to the permanent deformation behavior (resistance to rutting) at high operating temperatures [11]. The binder $\mathrm{B}$ has an average value of the ring and ball temperature. Knowing that in Algeria the temperature of $50^{\circ} \mathrm{C}$ is easily reached in the roadway this will increase certainly the risks of rutting in hot time [12], the risk of rutting in hot weather is not ruled out. The penetration index (PI) shows that the bitumen (B) has a high susceptibility to temperature change.

\section{Experimental Methods}

Penetration test according to ASTM D-5 was used to determine the consistency of a bitumen binder according to the following procedure [13]: bitumen is placed in a standard cup at $25^{\circ} \mathrm{C}$. A needle is then allowed to fall into the bitumen under a $100 \mathrm{~g}$ load for $5 \mathrm{~s}$. The length the needle penetrates into the bitumen during this time is expressed in units of $0.1 \mathrm{~mm}$. Soft bitumens exhibit high penetrations and harder bitumens low penetration values.

The test of softening point temperature was performed according to ASTM D36. The heated bitumen sample is placed in each of two brass rings. The rings are then placed in a bath of demineralised water/glycerol and a ball bearing is placed on each. The water/glycerol is heated at a rate of $5^{\circ} \mathrm{C} / \mathrm{min}$ until the binder deforms due to its decreasing viscosity with increasing temperature. The softening point temperature was taken as the temperature at which the sample became soft enough to allow the ball, enveloped in the sample material, to fall a distance of
$25.4 \mathrm{~mm}$. This was recorded as the ring and ball softening point temperature.

The susceptibility of bitumen temperature, that is to say the measurement of the change in consistency depending on the temperature, is characterized by a number called Penetration Index noted PI [14,15].

Pfeiffer and Van Doormaal in 1936 [16] have defined the thermal susceptibility of bitumens based on penetration index and stated that this index can take values ranging from -3 for asphalt very sensitive to +7 for bitumens with low thermal sensitivity.

In addition, the temperature susceptibility of the bitumens has been calculated in terms of penetration index (PI) using the results obtained from penetration and softening point tests. Temperature susceptibility is defined as the change in the consistency parameter as a function of temperature. A classical approach related to PI calculation has been given in the Shell Bitumen Handbook as shown with the following equation [17]:

$$
\mathrm{PI}=\frac{1952-500 \times \log \left(\text { pen }_{25}\right)-20 \times \mathrm{SP}}{50 \times \log \left(\text { pen }_{25}\right)-\mathrm{SP}-120}
$$

where, pen $_{25}$ is the penetration at $25^{\circ} \mathrm{C}$ and $\mathrm{SP}$ is the softening point temperature of bitumens. Nowadays, bitumen of straight run have negative PI generally between -1 and -2 , semi-blown bitumens thermally less susceptible have PI almost zero or slightly positive (from -0.2 to $+0.6)$. Industrial bitumen sealing have positive PI $(>+1)$ [15]. For asphalt "sol-like", penetrability indices were negative by cons for asphalt "gel-like" they are positive [16].

According to ASTM D2872-04, simulation of aging of bitumen was done by Rolling Thin-Film Oven Test (RTFOT). Accordingly, a moving film of bitumen was heated in an oven for $85 \mathrm{~min}$ at $163^{\circ} \mathrm{C}$.

The aging of bitumen was determined from changes in physical and rheological properties of bitumen, as measured before and after the oven treatment.

The most commonly used method of fundamental rheological testing of bitumen was by means of dynamic mechanical analysis (DMA) using oscillatory-type test. It generally conducted within the region of linear viscoelastic response.

These oscillatory tests were undertaken using controlledstress rheometer (Haake RS1, Germany). It applied oscillating shear stresses and strains to samples of bitumen sandwiched between parallel plates at different loading frequencies and temperatures. A temperature sweep was applied over the range $40^{\circ} \mathrm{C}-100^{\circ} \mathrm{C}$ at a fixed frequency of $10 \mathrm{rad} / \mathrm{s}$ and variable strain. The strain was chosen to be as small as possible to ensure measurement in the linear region, but large enough to allow sufficient torque readings. A frequency sweep was applied over the range $0.01-10 \mathrm{rad} / \mathrm{s}$ at variable temperatures $\left(40^{\circ} \mathrm{C}\right.$ to $\left.80^{\circ} \mathrm{C}\right)$. 
The binders rheological properties thus determined are appreciated by operating different curves plotted (isotherms, isochronous, Black and master).

\section{Results and Discussions}

\subsection{Aging Binders}

The simulation of the aging RTFOT shows an acceptable aging, according to the European specifications EN 12591 (Table 1).

Aged binders do not pose a risk of thermal fatigue cracking as their softening point does not belong to the interval (64 to 68) where the risk of cracking are not negligible [18].

Another indicator can be used to estimate the risk of thermal fatigue cracking; it is the evolution of the softening point during testing RTFOT. This value is limited to $8^{\circ} \mathrm{C}$ (EN 12591) for class $35 / 50$.

Increasing the ring and ball softening binder studied does not exceed $8^{\circ} \mathrm{C}$ showing that there is no risk of thermal fatigue cracking.

The value of temperature ball and rings obtained on the asphalt before RTFOT may fear, risk of permanent deformations if the evolution of the binder in the coating was low. But its strong growth during RTFOT suggests that these risks are limited, at least if the formula of the mix is correct. This fact is verified by the modulus measured by rheological tests.

The evolution of the softening point according to the temperature of aging is in a proportional manner (Figure 1). Indeed, the softening point increases of $0.2^{\circ} \mathrm{C}$ for a

Table 1. Binder characteristics aging.

\begin{tabular}{ccccc}
\hline & B & B_163 ${ }^{\circ} \mathrm{C}$ & B_173 ${ }^{\circ} \mathrm{C}$ & ${\text { B_ } 183^{\circ} \mathrm{C}}$ \\
\hline $\begin{array}{c}\text { Penetration } \\
(0.1 \mathrm{~mm})\end{array}$ & 27 & 24.8 & 19.8 & 18.3 \\
$\begin{array}{c}\text { Softening } \\
\text { point }\left({ }^{\circ} \mathrm{C}\right)\end{array}$ & 54.9 & 59.7 & 59.9 & 60.1 \\
PI & -1.33 & -0.55 & -1.00 & -0.05 \\
$\begin{array}{c}\Delta \text { Softening } \\
\text { point }\left({ }^{\circ} \mathrm{C}\right)\end{array}$ & - & 4.8 & 5 & 5.2 \\
\hline
\end{tabular}

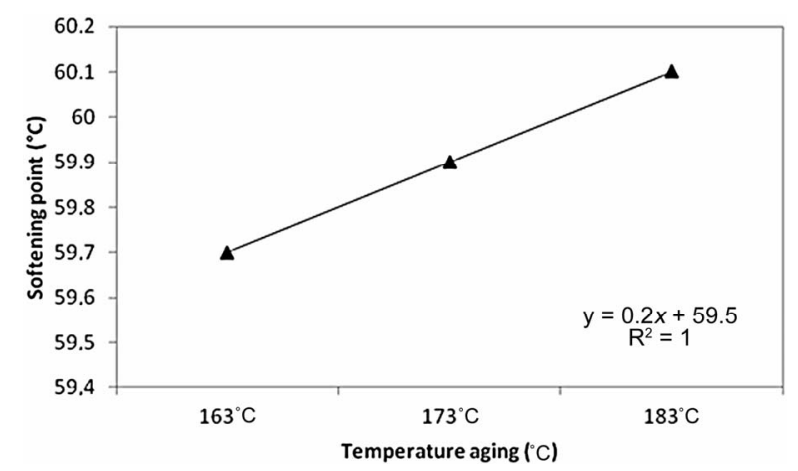

Figure 1. Softening point according to the aging temperature. $10^{\circ} \mathrm{C}$ change in temperature aging.

The evolution of the thermal susceptibility PI (Table 1) after RTFOT not improved thermal sensitivity (negative values).

\subsection{Rheological Behavior}

\section{1) Isotherms}

The isotherms of the complex modulus are plotted on Figure 2.

The complex modulus increases with frequency. For high temperature slope of the curve of the module is marked. In addition, the complex modulus isotherms show a small overlap area for high temperatures. This means that dispersion temperature and time are not equivalent in this region.

\section{2) Isochrones}

Isochrones of the complex modulus and the phase angle at $10 \mathrm{rd} / \mathrm{s}$, before and after RTFOT, are shown in Figure 3. The aging of the binder resulted a marked increase in stiffness binders with high operating temperatures thus reducing the thermal sensitivity. In addition, the decrease in phase angle increases the elastic contribution to the module [19]. The main ageing mechanism of bitumen is the loss of volatiles and oxidation, which leads to having higher viscosity and a bitumen that is stiffer than fresh bitumen [20].

\section{3) Black curves}

Figure 4 presents black curves of the binders before and after RTFOT. The analysis of these results shows that in the low frequency domain and high temperatures, the complex modulus $\mathrm{G}^{*}$ decreases strongly, while the phase angle approaches $90^{\circ}$ reflecting completely fluid behavior.

Higher values of phase angle indicate a tendency towards more viscous behaviour, whilst lower values indicate more elastic response [21].

The uniqueness of the curve Black binders is relatively good. Curves are not too "waves" due to poor implementation time/temperature. Discontinuities in the curve Black, often referred to as "waves" [19,22] reflect structural changes, based on changes in temperature, due to:

- Either the merger of certain chemical species such as certain paraffin;

- Or the modification of some physical links between asphaltene agglomerates.

Another phenomenon may be responsible for the formation of these waves [23] in the case of very paraffinic binders, relaxation due to dissolution/crystallization of paraffins is superimposed on the glass transition associated with the maltenes.

Activation of two different phenomena explains the dispersion increasingly important experimental points on the curve Black when the content of crystallizable fractions (paraffins) increases bitumen. This phenomenon 

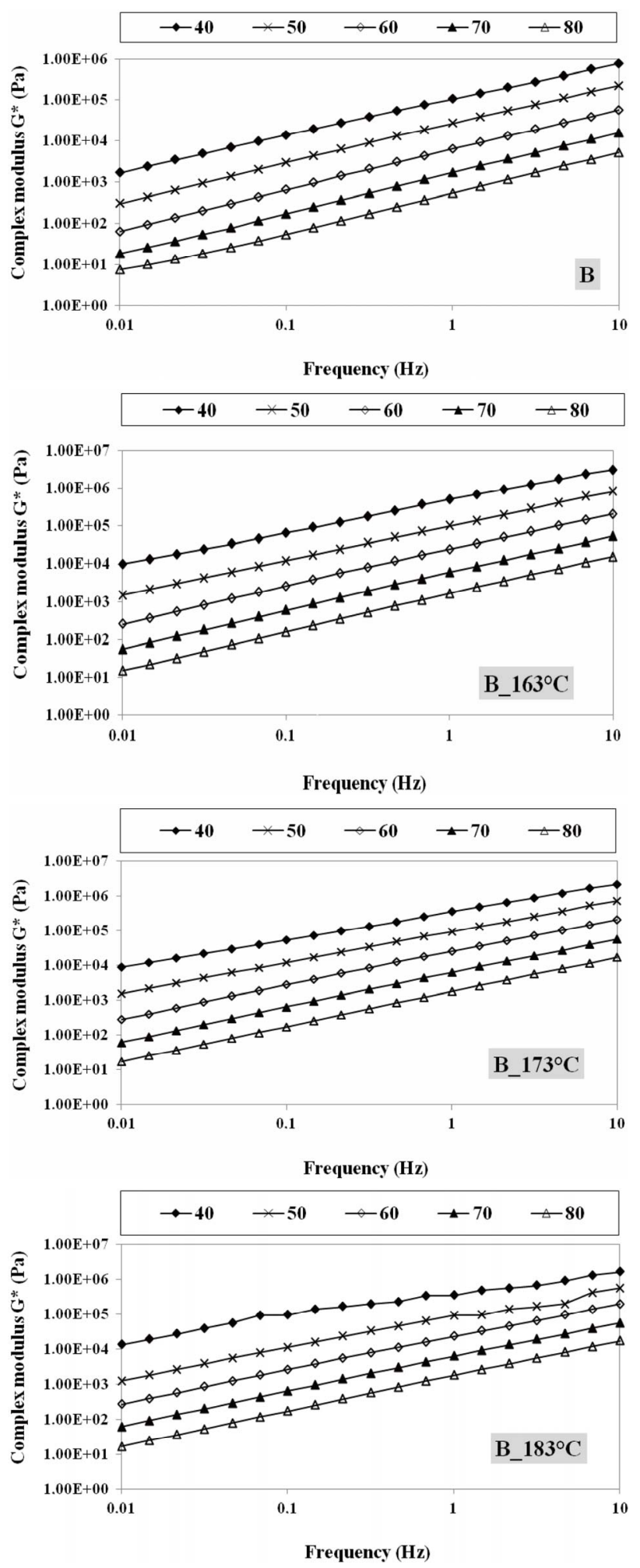

Figure 2. Isotherms of the complex modulus.

frequently observed in the aged binders in the coating or in situ occurs only rarely on new asphalt as is. Aging results in an increase in the structure reducing thermal and kinetic sensitivities. It may be that these binders are microscopically heterogeneous and contain asphaltenes highly interactive teaming agglomerates more or less stable with temperature and perhaps even the frequency.

4) Master curves

Master curves of complex modulus $\left(\mathrm{G}^{*}\right)$ can be traced to a reference temperature, by translating the different isotherms according to the frequency axis [24]. This property is called "time-temperature superposition principle (TTSP)" [25] as the translation procedure isotherms give a single master curve and continue only for the complex modulus. Figure 5 shows the master curve plotted for the bitumen at a temperature of $25^{\circ} \mathrm{C}$.

An examination of the complex modulus master cu-

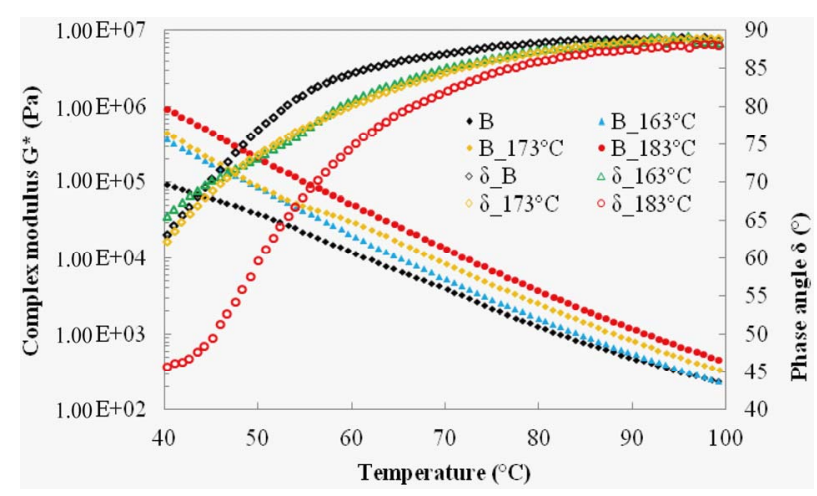

Figure 3. Isochrones of the complex modulus and phase angle.

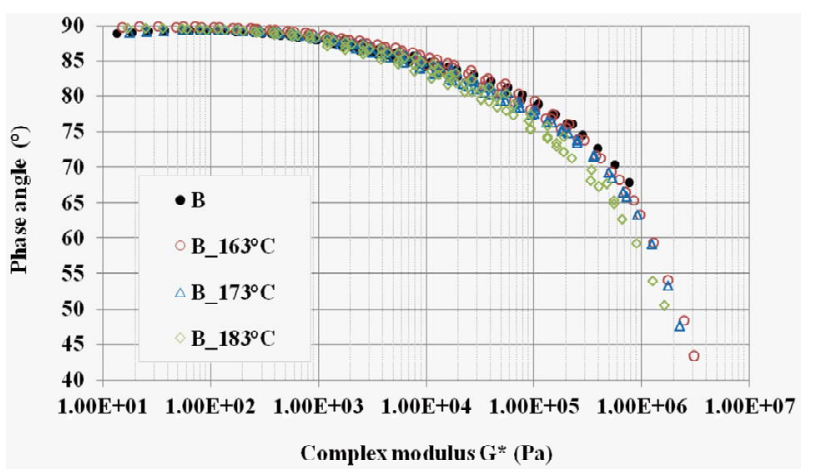

Figure 4. Black curves.

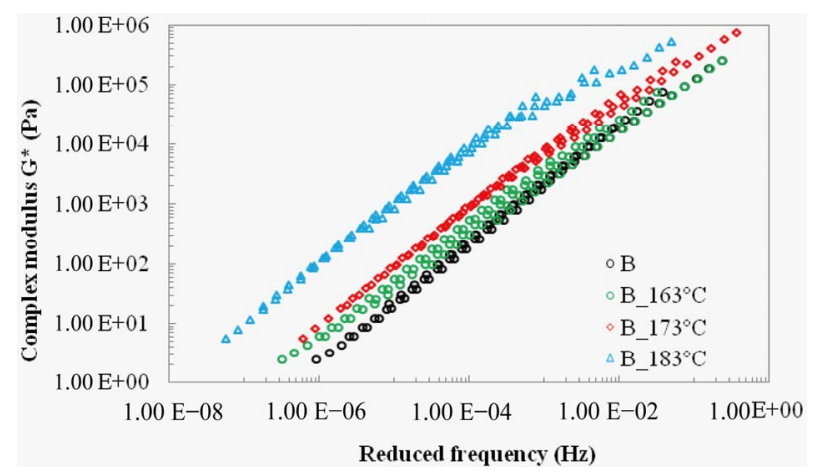

Figure 5. Master curve at $25^{\circ} \mathrm{C}$. 
rves obtained before and after RTFOT for different aging temperatures, show that the value of each isothermal shifts to values higher modules, especially for the aged bitumen to $183^{\circ} \mathrm{C}$. This increase in modulus results in a cure.

Note that the curves tend to join from a value of $10^{-1}$. Indeed, these isotherms also become less steep, for low temperatures indicating that the kinetic and thermal sensitivities decrease [15]. Table 2 gives the values of the constants $\mathrm{C} 1$ and $\mathrm{C} 2$ of Law WLF.

\subsection{Study of the Risk of Deformation of the Asphalt through the Performance of Bitumen Rheological}

The rheological characteristics measured on binders can be used to predict [19], given the Algerian climate, the type strain following:

- Permanent deformation (rutting);

- Thermal fatigue cracking;

In fact, according to research arising from the program SHRP (Strategic Highway Research Program) [26] the binder is responsible for $40 \%$ of rutting phenomenon, at $60 \%$ of the fatigue phenomenon.

\section{1) Risk of rutting}

To reduce the risk of rutting, the French technical advice [19], suggest the value of the complex modulus $\mathrm{G}^{*}$ at $7.8 \mathrm{~Hz}$ measured at a temperature $\mathrm{T} 1$ as an indicator [27-29] (in the case of this study $\mathrm{T} 1=64.6^{\circ} \mathrm{C}$ ). It must be greater than the critical value of $1.10^{4} \mathrm{~Pa}$.

This condition is checked for the binder studied (Table 3). The ratio $\mathrm{G}^{*} / \sin \delta$ is taken to SHRP specifications $[19,30]$ it is measured at $60^{\circ} \mathrm{C}$ and $1.6 \mathrm{~Hz}$. It presents the impact of the module with the phase shift value. SHRP specifications set indirectly and by means of the temperature, a minimum value is $1 \mathrm{KPa}$ report before RTFOT and a value of $2.2 \mathrm{KPa}$ after RTFOT. The ratios calculated for the four binders are higher than these limits.

Glita \& Conan (1996) [31] proposed the ratio $\mathrm{G}^{*} / \sin \varphi$ measured at $5 \mathrm{~Hz}$ and $60^{\circ} \mathrm{C}$ as a characteristic of bitumen (test conditions similar to that of the rutting test on asphalt), the greater its value, better resistance to creep.
Comparing the ratio given for each asphalt most aged binders are more rigid.

The risk of rutting evaluated by three criteria, although different, give the same trend: the binders studied do not present a risk of rutting.

The higher Temperature aging indices (TAI) was proposed [32] for indicate the effect of RTFO aging in rheological properties with respect to un-aged condition at high temperatures. The higher TAI values indicate a higher aging degree induced to bitumen. The indices use the measured rutting parameters at high in-service temperatures as follow:

$$
\text { High TAI }=\frac{\left(\mathrm{G}^{*} / \sin \delta\right)_{\mathrm{RTFOT}}}{\left(\mathrm{G}^{*} / \sin \delta\right)}
$$

The index values show that when the temperature of aging increases, the rutting resistance is better.

\section{2) Risk of thermal fatigue cracking}

To assess the risk of thermal fatigue cracking, French technical advice proposes as a requirement the value of the phase angle measured at $40^{\circ} \mathrm{C}$ and $7.8 \mathrm{~Hz}$ before RTFOT which must be greater than $45^{\circ}$ [33]. This criterion (Table 4) is verified for the binder studied.

\section{Conclusions}

The aging of the binder to the different temperatures studied is acceptable.

Thermal fatigue cracking was estimated from two physical criteria and a criterion based on rheology. Each criterion shows that the base binder is no risk of thermal fatigue cracking. However, it should always be considered a good formulation to avoid joining the zone of un-

Table 2. Values of the coefficients C1 and C2 of Law WLF.

\begin{tabular}{ccccc}
\hline $\begin{array}{c}\text { Law WLF } \\
\text { coefficients }\end{array}$ & B & B_163 ${ }^{\circ} \mathrm{C}$ & B_173 ${ }^{\circ} \mathrm{C}$ & B_183 ${ }^{\circ} \mathrm{C}$ \\
\hline $\mathrm{C} 1$ & 9.01 & 13.53 & 15.55 & 10.11 \\
$\mathrm{C} 2$ & 68.30 & 110.96 & 148.39 & 51.21 \\
\hline
\end{tabular}

Table 3. Valuation to risk of rutting.

\begin{tabular}{lccc}
\hline Criterion of rutting & B & $163^{\circ} \mathrm{C}$ & $173^{\circ} \mathrm{C}$ \\
\hline $\mathrm{G}^{*}\left(7.8 \mathrm{~Hz}, 64.6^{\circ} \mathrm{C}\right)[\mathrm{Pa}]$ & $4.9 \times 10^{4}$ & $15.8 \times 10^{4}$ & $16.7 \times 10^{4}$ \\
$\mathrm{G}^{*} / \sin \delta\left(1.6 \mathrm{~Hz}, 60^{\circ} \mathrm{C}\right)[\mathrm{Pa}]$ & $1.3 \times 10^{4}$ & $2.18 \times 10^{4}$ & $3.2 \times 10^{4}$ \\
$\mathrm{G}^{*} / \sin \delta\left(5 \mathrm{~Hz}, 60^{\circ} \mathrm{C}\right)[\mathrm{Pa}]$ & $2.8 \times 10^{4}$ & $11.5 \times 10^{4}$ & $5.4 \times 10^{4}$ \\
$\left(\mathrm{G}^{*} / \sin \delta\right)_{\mathrm{RTFOT}} /\left(\mathrm{G}^{*} / \sin \delta\right)$ & - & 1.67 & $12.8 \times 10^{4}$ \\
\hline
\end{tabular}

Table 4. Valuation to thermal fatigue cracking.

\begin{tabular}{cccccc}
\hline Criterion of thermal fatigue cracking & B & $163^{\circ} \mathrm{C}$ & $173^{\circ} \mathrm{C}$ & $183^{\circ} \mathrm{C}$ \\
\hline$\delta\left(7.8 \mathrm{~Hz}, 40^{\circ} \mathrm{C}\right)\left[{ }^{\circ}\right]$ & 68.1 & 55.05 & 53.43 & 49.15 \\
\hline
\end{tabular}


certainty and move forward to cracking.

The rheological analysis showed a marked increase in the stiffness of binders to high operating temperatures thus reducing thermal sensitivity. The binders studied do not present a risk of rutting. In so far as these risks may not be favoured by a high traffic load or an inadequate formulation of the mix.

The good behaviour at high temperatures should be accompanied by an adequate response of the binder at low temperatures, at which cracking effects can happen.

Decreasing the elasticity of the binder at low temperatures facilitates to avoid cracking, since the absorbed energy is more easily dissipated. In summary, a low elasticity is suitable at low temperatures to facilitate dissipation, but a high elasticity is convenient at high temperatures to avoid viscous flow of the bitumen binder.

This study showed any interest in the choice of mixing temperature of bitumens and modified bitumen in the asphalt. Indeed, the rigidity of the binder, so the asphalt, depends on this temperature. However, as is often the case in road, everything is a compromise, and especiallythe definition of basic requirements. To asphalt formulators and pavement designers choose the most appropriate temperature.

\section{REFERENCES}

[1] D. Whiteoak, "Shell Bitumen Handbook," Shell Bitumen UK, Riversdell Hause, 1990.

[2] M. Zargar, et al., "Investigation of the Possibility of Using Waste Cooking Oil as a Rejuvenating Agent for Aged Bitumen," Journal of Hazardous Materials, Vol. 233234, 2012, pp. 254-258. doi:10.1016/j.jhazmat.2012.06.021

[3] D. Mastrofini and M. Scarsella, "The Application of Rheology to the Evaluation of Bitumen Ageing," Fuel, Vol. 79, No. 9, 2000, pp. 1005-1015. doi:10.1016/S0016-2361(99)00244-6

[4] I. Gawel and K. Baqinska, "Effect of Chemical Nature on the Susceptibility of Asphalt to Aging," Petroleum Science and Technology, Vol. 22, No. 9, 2004, pp. 1261-1271.

[5] X. H. Lu and U. Isacsson, "Effect of Aging on Bitumen Chemistry and Rheology," Construction and Building Materials, Vol. 16, No. 1, 2002, pp. 15-22. doi:10.1016/S0950-0618(01)00033-2

[6] A. B. Brown, et al., "Steric Hardening of Asphalts," Proceedings of the Association of Asphalt Paving Technologists, Vol. 26, No. 26, 1957, pp. 486-494.

[7] H. U. Bahia and D. A. Anderson, "Glass Transition Behaviour and Physical Hardening of Asphalt Binders," Journal of the Association of Asphalt Paving Technologists, Vol. 62, 1993, pp. 93-129.

[8] S. Wu, et al., "Rheological Properties for Aged Bitumen Containing Ultraviolate Light Resistant Materials," Construction and Building Materials, Vol. 33, 2012, pp. 133138. doi:10.1016/j.conbuildmat.2012.01.019
[9] S. H. Firoozifar, et al., "The Effect of Asphaltene on Thermal Properties of Bitumen Chemical," Engineering Research and Design, Vol. 89, No. 10, 2011, pp. 2044-2048. doi:10.1016/j.cherd.2011.01.025

[10] M. Yilmaz, et al., "Investigation of Complex Modulus of Base and EVA Modified Bitumen with Adaptive-Network-Based Fuzzy Inference," System Expert Systems with Applications, Vol. 38, No. 1, 2011, pp. 969-974. doi:10.1016/j.eswa.2010.07.088

[11] B. J. Dongmo-Engeland, "Characterization of Rutting Deformation of Bituminous Pavement," Ph.D. Thesis, National Institute of Applied Sciences of Lyon, Lyon, 2005.

[12] S. Saoula, et al., "The Study of the Improvement of Mechanical Performance of Asphalt Modified by the Optimization of Mixing Time of EVA Bitumen," AIP Conference Proceedings, Vol. 1400, 2011, pp. 262-267. doi:10.1063/1.3663125

[13] N. Dehouche, et al., "Influence of Thermo-Oxidative Aging on Chemical Composition and Physical Properties of Polymer Modified Bitumens," Construction and Building Materials, Vol. 26, No. 1, 2012, pp. 350-356. doi:10.1016/j.conbuildmat.2011.06.033

[14] M. Harlin, "Bitumen: Properties, Characteristics, Specifications and Testing Laboratory," National School of Bridges and Roads, Paris, 1992.

[15] H. Di Benedetto and J. F. Corte, "Bituminous Road Materials 1: Description and Properties of Components," Lavoisier, 2004.

[16] O. Solomatnikova, "Rheological Behavior and Cohesive and Adhesive Properties of Bituminous Binders," Memory of Master of Applied Science, University of Laval, Quebec, 1998.

[17] A. Topal, "Evaluation of the Properties and Microstructure of Plastomeric Polymer Modified Bitumens," Fuel Processing Technology, Vol. 91, No. 1, 2010, pp. 45-51. doi:10.1016/j.fuproc.2009.08.007

[18] S. Gazeau, et al., "Application of Differential Scanning Calorimetry (DSC) to the Characterization of Ethylene Copolymers Modified Bitumen," Proceedings of the 1 st Eurasphalt and Eurobitume Congress, Strasbourg, 7-10 May 1996.

[19] G. Ramond, et al., "Caractéristiques de Bitumes Utilisés en Algérie," Bulletin de Liaison Ponts et Chaussées, Vol. 225, 2000, pp. 3-11.

[20] G. Holleran, et al., "Rejuvenation Treatments for Aged Pavements," Transport Research Board, 2006.

[21] I. Widyatmoko and R. Elliott, "Characteristics of Elastomeric and Plastomeric Binders in Contact with Natural Asphalts," Construction and Building Materials, Vol. 22, No. 3, 2008, pp. 239-249. doi:10.1016/j.conbuildmat.2005.12.025

[22] G. Ramond and M. Epinat, "Contribution à l'Élaboration d'un Mode Opératoire de Mesure du Module Complexe," Bitume Actualités, No. 101, 2000, pp. 37-42.

[23] F. Olard, "Thermomechanical Behavior of Bituminous Mix Asphalt with Low Temperatures, Relationship between Binder Properties and Asphalt," Ph.D. Thesis, 
INSA de Lyon, France, 2003.

[24] F. Olard, et al., "Rhéologie des Bitumes: Prédiction des Résultats des Tests de Fluage BBR à Partir des Résultats de Module Complexe," Bulletin des Laboratoires des Ponts et Chausses, No. 252-253, 2004, pp. 3-15.

[25] G. D. Airey, "Rheological Evaluation of Ethylene Vinyl Acetate Polymer Modified Bitumens," Construction and Building Materials, Vol. 16, No. 8, 2002, pp. 473-487. doi:10.1016/S0950-0618(02)00103-4

[26] J. J. Lesage, et al., "Vers une Approche Rhéologique des Liants Bitumineux et Prédictive des Performances Mécaniques des Enrobés," Analusis, Vol. 23, 1995, pp. 492496.

[27] Y. Marciano, et al., "Les Spécifications Superpave: une Contribution Shell au Décryptage. Carte de France des PG (Performance Grade)," Revue Générale des Routes et Aerodromes, No. 748, 1997, pp. 55-59.

[28] C. Such and G. Ramond, "Les Spécifications SHRP sur les Bitumes et la Température de Ramollissement Bille et Anneau," Bulletin de Liaison Ponts et Chausses, No. 200, 1995, pp. 3-12.
[29] C. Such and G. Ramond, "Les Spécifications SHRP une Tentative de Décryptage," Revue Générale des Routes et Aérodromes, No. 730, 1995, pp. 57-59.

[30] M. Barral, et al., "Novel Bituminous Mastics for Pavements with Improved Fire Performance," Construction and Building Materials, Vol. 30, 2012, pp. 650-656. doi:10.1016/j.conbuildmat.2011.12.055

[31] S. Glita and J. Conan, "Rheological Analysis of 7 Hard 10/20 Bitumens" Proceedings of the 1st Eurasphalt and Eurobitume Congress, Strasbourg, 7-10 May 1996.

[32] S. Dessouky, et al., "Effect of Pre-Heating Duration and Temperature Conditioning on the Rheological Properties of Bitumen," Construction and Building Materials, Vol. 25, No. 6, 2011, pp. 2785-2792. doi:10.1016/j.conbuildmat.2010.12.058

[33] G. Ramond and M. Pastor, "Rappel des Notions de Base et des Principes d'Exploitation du Module Complexe," Report No. 135 D96, Central Laboratory of Roads and Bridges, France, 1996. 